\title{
THE POLICY ENVIRONMENT AND RELATIVE PRICE EFFICIENCY OF EGYPTIAN PRIVATE SECTOR MANUFACTURING: 1987/88-1995/96
}

\author{
LULLIT GETACHEW ${ }^{\mathrm{a}}$ AND ROBIN C. SICKLES ${ }^{\mathrm{b} *}$ \\ a Pacific Economics Group, Madison, WI, USA \\ ${ }^{\mathrm{b}}$ Department of Economics, Rice University, Houston, TX, USA
}

\begin{abstract}
SUMMARY
We study the impact of policy and institutional constraints, and reforms undertaken to remedy them, on relative price efficiency and cost of the private manufacturing sector of Egypt. We undertake this study using a generalized cost function, which subsumes the standard neoclassical cost function as a special case. This approach allows us to assess the impact of such constraints, which include labor market, energy and financial sector ones, on relative prices and the structure of production, including factor demands, shares and cost. Our findings indicate the presence of substantial distortions in relative prices, and hence on cost, due to the policy environment. We also find improvements in relative price efficiency and cost performance as a result of policy reforms initiated to remove the constraints. Copyright (c) 2007 John Wiley \& Sons, Ltd.
\end{abstract}

Received 21 January 2004; Revised 26 February 2006

\section{INTRODUCTION}

Many observers have come to believe that complex systems of policy and bureaucratic burdens are major obstacles to the development of the manufacturing sector in many developing countries (Tybout, 2000). This is true of Egypt, where such institutional constraints have hampered the activities of the private sector in general, and the private manufacturing sector in particular.

Among the factors that constrain private sector development in Egypt are financial sector policies, tax administration, energy policies, labor market regulation and bureaucratic systems. To an extent, some of these problems are not unique to Egypt; they were, and in some cases still are, widespread among many developing countries, particularly among those that followed import substitution industrialization. This makes Egypt a good case study of the effect these policy constraints have on the private sector.

In this study we analyze the effect of these constraints on the cost performance of the Egyptian private manufacturing sector from the mid 1980s to the mid 1990s. We undertake this study by estimating a generalized cost function and relative price efficiency. Relative price efficiency estimates capture the net effect of the various policy distortions in the macro environment. In particular, distortions in the macro environment affect relative input prices in unobserved ways and the behavioral assumption of cost minimization allows the identification of relative market price divergence from relative shadow prices. We also study the impact of economic reforms,

\footnotetext{
* Correspondence to: Robin C. Sickles, Department of Economics, Rice University, MS 22, Houston, TX 70005, USA.

E-mail: rsickles@ rice.edu

Contract/grant sponsor: USAID; Contract/grant number: 263-00-96-00001-00.
}

Copyright (C) 2007 John Wiley \& Sons, Ltd. 
undertaken since 1991, on the sector's relative price and productive performances. We estimate separate generalized cost functions for the pre- and post-reform periods for this purpose.

In part, the motivation for this study stems from the finding that the reforms of the early 1990s have had a positive impact on output and total factor productivity growth of the sector. Thus, the study period of the mid 1980s to the mid 1990s provides an appropriate time period over which we can analyze the outcome of this natural policy experiment. In the post reform period, spanning the years 1991/92-1995/96, the quantity index of output for the private manufacturing sector grew at a rate of $5.4 \%$ per year and the quantity index for inputs grew at $3.4 \%$ per year. In addition, total factor productivity (TFP) grew at a rate of $2 \%$ a year over this period. ${ }^{1}$ The TFP profile for the 1987/88-1995/96 period is displayed in Figures 1 and 2. In Figure 1 we can see the temporal patterns of the output and input indices, normalized to one in the base period of 1988/87. Growth in both was rather equal until the reforms of the early 1990s. There was a ratcheting down in the input quantity index about 1991. At the same time, the TFP index (Figure 2) rose substantially. Although some of the gains from the reforms of the early 1990s appear to have lessened toward

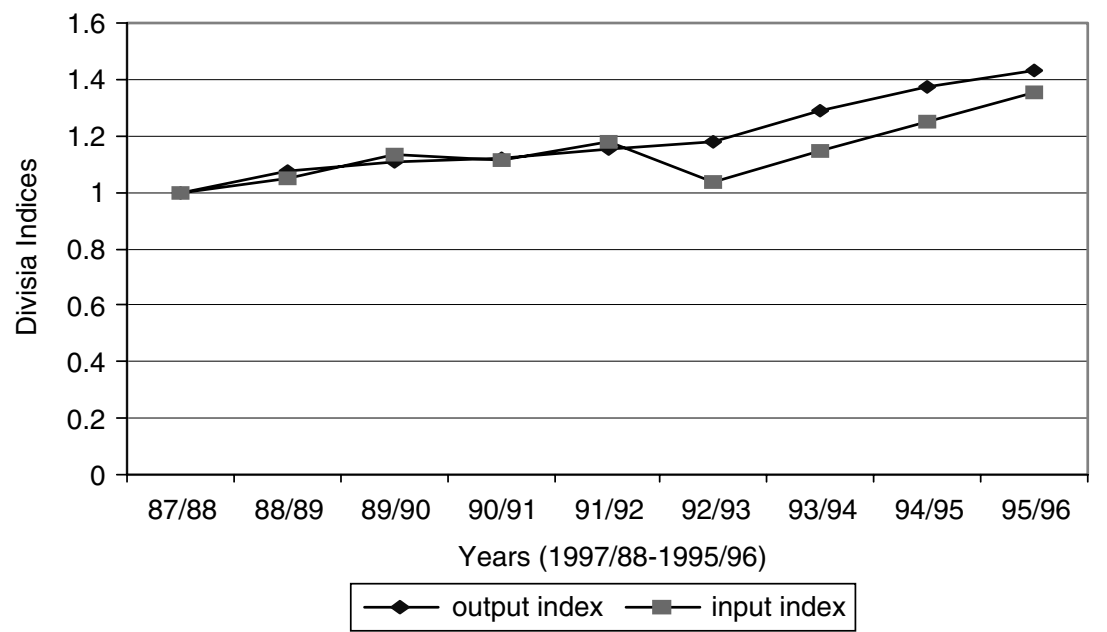

Figure 1. Divisia indices of output and input for private sector manufacturing (1987/88-1995/96)

${ }^{1}$ For a panel dataset, the chaining approach of the Divisia and the hypothetical sector approach of Caves
are used to construct a TFP index. A measure of TFP at time $t$ for sector $f$ relative to the hypothetical sector
represented by the terms with a bar over them, is given by
\[ \begin{aligned} \ln T F P_{f t} & =\left(\frac{1}{2} \sum_{j=1}^{m}\left(R_{f j t}+\overline{R_{j t}}\right)\left(\ln Y_{f j t}-\overline{\ln Y_{j t}}\right)+\sum_{s=2}^{t} \frac{1}{2} \sum_{j=1}^{m}\left(\overline{R_{j s}}+\overline{R_{j, s-1}}\right)\left(\overline{\ln Y_{j s}}-\overline{\ln Y_{j, s-1}}\right)\right) \\ & -\left(\frac{1}{2} \sum_{i=1}^{n}\left(S_{f i t}+\overline{S_{i t}}\right)\left(\ln X_{f i t}-\overline{\ln X_{i t}}\right)+\sum_{s=2}^{t} \frac{1}{2} \sum_{i=1}^{n}\left(\overline{S_{i s}}+\overline{S_{i, s-1}}\right)\left(\overline{\ln X_{i s}}-\overline{\ln X_{i, s-1}}\right)\right)\end{aligned} \]

where $R_{f j t}$ is the revenue share of output $j$ for sector $f$ in period $t$ and $m$ is the number of outputs, $S_{f i t}$ is the cost share of input $i$ for sector $f$ in period $t$ and $n$ is the number of inputs, $X_{f i t}$ and $Y_{f j t}$ are input $i$ and output $j$, respectively, of sector $f$ in period $t$. 


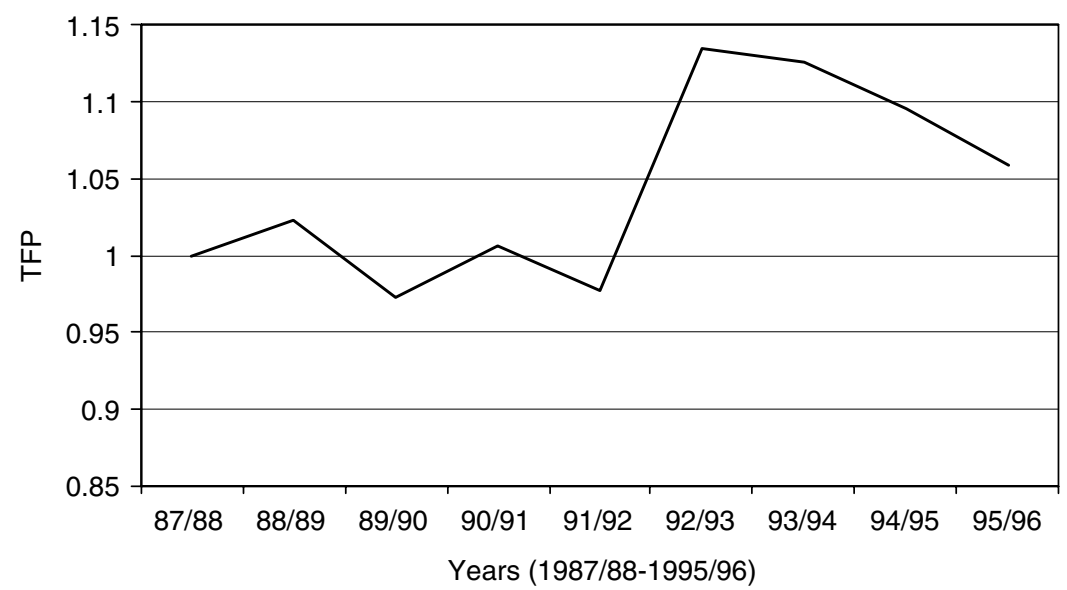

Figure 2. Total factor productivity in private sector manufacturing (1987/88-1995/96)

the end of our sample period, these gains in total factor productivity are nonetheless quite strong (Sickles and Getachew, 2000).

Given these positive developments in TFP, we study the effect of the reforms on relative price and cost efficiency, drawing on the literature that examines the impact of policy distortions on optimizing behavior. This literature is useful in the analysis of the structure of production where producers are likely to face binding constraints on their decision-making. It extends duality theory by incorporating the impact of such constraints on firm behavior.

Generally the dual representation of production allows the use of flexible functional forms and, through simple derivation, the use of a system of input demand equations to study production technology. The standard neoclassical cost function used by this approach rests on the assumption of cost-minimizing behavior given market prices on the part of producers. In the presence of policy and related constraints in the operating environment, however, the assumption of cost minimization, given market prices, is unlikely to hold. Instead, the use of a generalized cost function, which incorporates the impact of such constraints, is a more useful approach. This approach incorporates optimizing behavior subject to shadow prices that deviate from market prices due to the constraints. Thus, it allows the identification of the impact of such constraints on total cost, factor demand and factor shares.

In the next section, we detail the institutional background of the study. This is followed by Section 3, where we present the generalized cost function and the estimation method, and Section 4, where we describe the data. We present empirical results in Section 5 and concluding remarks in Section 6.

\section{INSTITUTIONAL BACKGROUND}

\subsection{The Private Sector}

Throughout the study period, but to a decreasing extent over time, Egypt's private sector boundaries have been limited. The state has been present in many areas of economic activity, either as a monopoly or as the largest player. Overall, four types of public institutions have been present 
in the economic arena: local government ventures, service companies, economic authorities, and public enterprises. The latter, although not legally granted monopolistic rights, have operated in almost all productive activities ranging from cement and iron to hotels, and dominate the Egyptian financial system.

Despite the heavy presence of these public enterprises in economic activity, the private sector's economic contribution is very high. In general, the private sector provides most of the employment in Egypt - in fact over two-thirds of total employment - and pays marginally better salaries than the public sector: on average, US \$565 per year for a private sector job versus US \$536 per year for a public sector one in FY 1992 (World Bank, 1994).

The private sector is classified into three sub-sectors: the formal, informal, and investment sectors. The investment sector is more export oriented than the other two, accounting for $64 \%$ of total private industrial exports in 1995/96, while the formal and informal private sectors accounted for $11 \%$ and $25 \%$ of such exports in 1995/96, respectively. The difference between the formal and investment sectors from the informal sector is that the former need to maintain organized accounting records and submit reports for auditing. In addition, these two sub-sectors mostly comprise medium and large enterprises (MLEs), which are ones employing 10 to 99, and 100 or more workers, respectively. The informal sector largely contains micro and small enterprises (MSEs), which employ fewer than 10 workers (World Bank, 1994).

Private sector presence in the industrial sector, which includes both manufacturing, and mining and quarrying, has grown since the early 1990s. Total private output by the industrial sector increased from $45 \%$ of the total in 1992 to about $50 \%$ in 1996, while employment in the sector rose from $32 \%$ to $40 \%$ of the total over this same period. Industry's share of total GDP rose from $9 \%$ to over $14 \%$, while the private manufacturing share of GDP rose from $4.2 \%$ to over $7 \%$ over the same period. The formal sector dominates private industrial activity, accounting for about half its output. The investment and informal sectors make up the remaining half, each accounting for around a quarter of the total. ${ }^{2}$ The informal sector, however, employs about $58 \%$ of the total private industrial labor force, while the formal and investment sectors employ $20 \%$ and $22 \%$ of the total, respectively (Industrial Production Statistics, 1990/91-1995/96).

\subsection{The Business Environment}

One of the factors that constrains private sector activity, and is common to many developing countries, is bureaucratic red tape. The International Trade Administration's (1999) Country Commercial Guide to Egypt points to red tape as 'a key business impediment in Egypt, including a multiplicity of regulations and regulatory agencies, delays in clearing goods through customs, arbitrary decision-making, high market entry transaction costs, and a generally unresponsive commercial court system'. A typical bureaucratic obstacle is a complicated and time-consuming licensing requirement to start a private business or expand capacity (Tesche and Tohamy, 1994).

In addition to this, several policy programs form barriers to private business activity. Among these are financial sector policies, which affect private sector activity by distorting the cost of funds. Three such distortionary undertakings in this area are nominal interest rate ceilings, administrative credit allocations and foreign exchange controls. The government had a policy of setting ceilings

\footnotetext{
${ }^{2}$ The large contribution to output by medium and large enterprises (MLEs) in the industrial sector is unlike the case in the other sectors of the economy where MSEs dominate. 
on nominal interest rates on both the deposit and lending sides. For instance, from 1982 onwards, until the reforms of 1991, the rates on three-month time deposits were set at $8.5 \%$, while the lending rate was set at 15\% (Abdel-Khalek, 2001, p. 10). The government also had a policy of administering credit whereby it gave priority to funding the public sector. For example, government and public enterprises enjoyed monopoly access to long-term loans from the National Investment Bank, which held $25 \%$ of total deposits in 1992. In addition, the government used foreign exchange controls to allocate resources centrally; it set up different exchange rates administratively where favorable rates were used for public sector imports and restricted for private sector ones (Harik, 1997, pp. 110-114).

Tax administration policy is another factor that affects the cost of capital. Egypt relied on a system of multiple taxation that resulted in high taxes on capital. This system included corporate taxes, which are taxes on profits; personal income taxes, which include taxes on commercial and industrial profits; fiscal stamp tax on the capital of companies; and tax on sales, which are assessed on capital goods but not deducted from corporate and personal tax assessments (Giugale and Mobarak, 1996, p. 74).

The energy policy adopted by the government is another source of distortion in the input use of the private sector. Since the early 1970s, the government of Egypt has intervened heavily in the domestic energy market in a manner that typified such intervention among other Arab countries. The main form of this intervention is price control, whereby domestic fuel prices are set below international spot prices. The motivation for 'isolating' domestic prices from international spot prices is partly to encourage growth, but it is primarily to protect low- and middle-income groups from exogenous price changes. The extent of this control is evidenced by comparing the prices of major oil products faced by end users in Egypt with the international spot prices for them in 1980 and 1994 (Table I). Absent government price ceilings, domestic energy users would have faced the international spot prices since all these products are tradable on the world market (Faris Al-Faris, 1997).

On the labor front, labor market regulation in Egypt, coded principally through Labor Law 137, impacts the effective price of labor that private manufacturing employers face. Among its provisions are laws that guarantee lifetime job security for workers. This provision requires a written contract specifying the nature of the work and agreed compensation for each employee. Once a three-month probationary period has passed, the law stipulates that a worker cannot be dismissed as long as the contract remains in effect. Contracts are either for definite duration, i.e., temporary, or for indefinite duration, i.e., permanent. Temporary contracts automatically become permanent if renewed after the initial contract expires. Dismissal is allowed only following complex and costly procedures in cases of severe offenses, which include adopting a false identity or committing a 'grave' error.

The provision that guarantees lifetime job security applies to public as well as to private sector workers who are hired under a contract. It is binding on public sector firms. As indicated in the

Table I. End user spot prices for major oil products (US \$/liter)

\begin{tabular}{lllllllll}
\hline Fuel type & Gasoline & & Kerosene & \multicolumn{3}{c}{ Diesel } & & \multicolumn{3}{c}{ Heavy fuel } \\
\hline Year & 1980 & 1994 & 1980 & 1994 & 1980 & 1994 & 1980 & 1994 \\
Egypt & 0.17 & 0.28 & 0.04 & 0.09 & 0.04 & 0.08 & 0.01 & 0.03 \\
International & 0.37 & 0.17 & 0.10 & 0.18 & 0.34 & 0.17 & 0.23 & 0.11 \\
\hline
\end{tabular}


2001 Country Report on Economic Policy and Trade Practices (2002) on Egypt, the larger private sector firms also abide by the government-mandated labor laws and its standards. ${ }^{3}$ Since large and medium enterprises employ close to half of private industrial sector workers, the various provisions of the labor law are expected to have significant effect on the sector.

As detailed in Fallon and Lucas (1991), lifetime job security regulation raises the cost of employment by posing an obstacle to adjusting the workforce in response to changing market conditions. In particular, it raises turnover costs since firms must incur additional costs to persuade workers to quit or retire. It also raises the cost of adjusting the composition of the workforce due to dismissals, for disciplinary reasons, and the process of on-the-job screening. ${ }^{4}$

Even when some private sector employers are able to avoid complying with the job security provision of the law, by hiring temporary employees without legal contracts, they are affected by another aspect of Egyptian labor market policy. This effect, although indirect, is tied to the government's long-standing policy of guaranteeing public sector employment for all secondary and university graduates. Since the permanence of public sector employment is guaranteed, this policy engenders a strong preference for employment in this sector among graduates. In addition, centralized wage-setting rules for public sector workers, which offer automatic wage increases, and more desirable non-wage benefits, such as generous leave provisions, make public sector employment more attractive (Assaad, 1997). ${ }^{5}$ As a result of preferences for public sector employment created by this policy, there is likely to be an upward pressure on the effective price of labor faced by private sector employers.

\subsection{The Reforms}

Egypt initiated its structural adjustment program at the start of 1991. In general, the aim of the reforms was to orient the planned economy towards a market-based one. Initial efforts focused on macro-economic stabilization. At the same time, the government undertook steps to liberalize the economic environment and alleviate the bureaucratic burden in Egypt. For instance, it reduced the

\footnotetext{
${ }^{3}$ In addition to the job security provision, such standards include the minimum wage, bonus payments and benefits (Assaad, 1996).

${ }^{4}$ In their study on the impact of job security regulations in India and Zimbabwe, Fallon and Lucas find substantial decline in labor demand among manufacturing firms in both countries following the introduction of such laws. In Zimbabwe, the government adopted a new Employment Act in 1980, requiring employers to get permission to fire or lay off workers. Similarly in India, the Industrial Disputes Act of 1976 required written permission from the state government to close a plant or retrench workers. The job security provisions of both countries, at the time, differed from those in most countries due to their permission requirement.

Using data from the manufacturing sectors of India, covering the years 1956/60 through 1981/82, and Zimbabwe, covering the years 1960/61 through 1984/85, the authors estimate a richly specified labor demand function. This demand function captures the impact of these laws through a job security dummy, which has a negative and statistically significant estimate indicating a decline in labor demand due to the restrictive labor laws. They also investigate and find no evidence that employers offset the effect of the job security provisions by lowering wages or by increasing hours per employee. As a result, they conclude that the introduction of these regulations in the two countries significantly reduced the demand for labor at given levels of output.

${ }^{5}$ A much publicized event in 1992 illustrates the extent of workers' preference for public sector employment. In the new industrial city Tenth of Ramadan, during a celebration honoring outstanding workers, the Minister of Manpower and Vocational Training wanted the names of workers in the new industrial establishments for the purposes of removing them from the queue of graduates waiting for government jobs. Despite the well-paying jobs with benefits that the workers had in these firms, they chose to resign on mass so as not to lose their place in the queue for government jobs. When asked to explain their action, many expressed the premium they placed on securing government jobs that are guaranteed for life, offer flexible working hours and conditions, and often provide compensation on par with the private sector (Assaad, 1996).
} 
time to obtain private sector investment licenses, required to start a business, to a maximum of two weeks. It also eliminated the requirement of detailed project evaluations for new investments or expansions (Tesche and Tohamy, 1994).

Financial sector reforms addressed interest rate as well as foreign exchange policies. Starting in 1991, banks were allowed to set deposit interest rates freely. As a result, the deposit rate on the three-month time deposits, which had remained at $8.5 \%$ since 1982, fluctuated from $17.2 \%$ to $13.5 \%$ from June 1991 to June 1993. This led to a rise in LE-denominated deposits in the banking system from $44 \%$ of the total in 1989 to $68 \%$ in 1993. (LE refers to the Egyptian pound). In addition, the government discontinued the system of administrative allocation of bank credit (Giugale and Mobarak, 1996, p. 117). It also eliminated discretionary allocation of foreign exchange by the banking system (Abdel-Khalek, 2001, pp. 50, 69-70, 76).

Tax reforms focused on replacing the multiple taxation system by the unified tax system on income. This new system unified revenues collected from commercial and industrial profits (Tesche and Tohamy, 1994). It also cut the number of tax brackets from 21 to 7, and reduced the maximum rate from $65 \%$ to $50 \%$ (Giugale and Mobarak, 1996, p. 87).

Energy policy reforms were also initiated in 1991. These involved raising domestic petroleum product and natural gas prices to achieve parity with international prices by 1995 (Abdel-Khalek, 2001, pp. 49-50). Table II shows the development of domestic energy prices in the initial years of the post-reform period.

Labor law reforms, in the few years following 1991, remained elusive. In 1991, the government set up a committee to draft new labor legislation. This committee had representatives from the labor union, business, the Ministry of Labor, the local legal community and the International Labor Organization (ILO). The committee's work progressed slowly as labor representatives resisted changes to job security provisions, while the government and business representatives resisted changes that would allow workers the right to strike. A draft was agreed to in 1994, but its submission to parliament was delayed repeatedly. It was finally submitted to Parliament and passed in the spring of 2003 (Posusney, 2003). ${ }^{6}$ Although the labor law was not formally amended until 2003, the government had instituted a de facto labor policy change by no longer guaranteeing public sector jobs for all graduates in the early 1990s.

The number and scope of private sector policy reforms initiated in 1991 were substantial and substantive. Our study thus examines the impact these reforms had on distortions in the private manufacturing sector of Egypt. We develop the generalized cost model used for this purpose in the next section. The generalized cost model will assist us in measuring the extent of distortions in factor allocations engendered by old policies and the degree to which they are ameliorated by policy initiatives that make up the 'reforms'.

Table II. Domestic energy price reform (petroleum and natural gas), 1991-1993

\begin{tabular}{lc}
\hline Date & Weighted average domestic energy price \\
\hline May 1991 & Raised to 46\% of world prices \\
June-July 1992 & Raised to 80\% of world prices \\
December 1992 & Raised to 83\% of world prices \\
\hline
\end{tabular}

\footnotetext{
${ }^{6}$ The legislation, which clearly does not have an impact on the firms in our study, allows multiple renewals of temporary contracts, effectively ending lifetime job guarantees, but still requires government approval for mass layoffs. 


\section{THE GENERALIZED COST MODEL}

\subsection{The Private Sector}

The generalized cost model, subsuming the standard neoclassical model as a special case, is developed in Atkinson and Halvorsen (1984) and Evanoff et al. (1990). In addition, Good et al. (1991, 1997) develop a similar model which differs in the specification of shadow prices. The standard neoclassical cost function is based on the assumption that firms minimize cost subject to an output constraint:

$$
\min _{X} C=P^{\prime} X \text { s.t. } f(X) \leq Q
$$

where $P$ and $X$ are $h \times 1$ vectors of price and quantity of inputs, $f(X)$ is a well-behaved production function, and $Q$ is output. ${ }^{7}$ The Lagrangian for the firm's constrained cost minimization is then

$$
L=P^{\prime} X-v(f(X)-Q)
$$

and from the first-order conditions for cost minimization we obtain

$$
\frac{P_{i}}{P_{j}}=\frac{f_{i}}{f_{j}} \text { for } i \neq j=1 \ldots h
$$

The equality of the marginal rate of technical substitution (MRTS) to the ratio of the market price of inputs gives the optimal combination of inputs that minimize cost. ${ }^{8}$

Now suppose $R_{c}$ additional constraints exist due to the policy environment. The constraint can be written as $R(P, X ; \varphi)$, where $R$ is an $R_{c}$-dimensional function in $(P, X)$ and $\varphi$ is a vector of parameters (Lasserre and Ouellette, 1994). With the additional constraint, the firm's cost minimization problem becomes

$$
\min _{X} C=P^{\prime} X \text { s.t. } f(X) \leq Q \text { and } R(P, X ; \phi) \leq 0
$$

The Lagrangian for the firm's constrained optimization then becomes

$$
L=P^{\prime} X-v(f(X)-Q)-\sum_{r=1}^{R_{c}} \lambda_{r} R_{r}(P, X ; \phi)
$$

\footnotetext{
${ }^{7}$ In particular, the production function is assumed to be twice continuously differentiable, monotonic, $(((\partial f) /(\partial X)) \geq 0)$ and quasi-concave $\left(\theta \neq 0\right.$ and $((\partial f) /(\partial X))^{\prime} \theta=0$, which implies $\theta^{\prime}\left(\left(\partial^{2} f\right) /\left(\partial X^{2}\right)\right) \theta \leq 0$. Here $\theta$ is $h \times 1$ vector).

${ }^{8}$ These input demand functions are assumed to be continuously differentiable, homogeneous of degree zero in $P$, and to have a symmetric matrix of price effects, $\left(((\partial X) /(\partial P))=((\partial X) /(\partial P))^{T}\right)$, which is negative-definite, $\theta^{\prime}((\partial X) /(\partial P)) \theta<0$. The associated cost function is then assumed to be twice continuously differentiable, increasing in $(P, Q)$ or monotonic, concave in $P,\left(\left(\partial^{2} C\right) /\left(\partial P^{2}\right)\right)<0$, homogeneous of degree one in $P$ and having the derivability property (Shepard's lemma) $((\partial C) /(\partial P))=X$. 
where $\lambda_{r}, r=1 \ldots R_{c}$, are the Lagrangian multipliers associated with the $R_{c}$ additional constraints. The first-order conditions for cost minimization now give

$$
\frac{f_{i}}{f_{j}}=\frac{P_{i}+\sum_{r=1}^{R_{c}} \lambda_{r} \partial R_{r} / \partial X_{i}}{P_{j}+\sum_{r=1}^{R_{c}} \lambda_{r} \partial R_{r} / \partial X_{i}}=\frac{P_{i}^{e}}{P_{j}^{e}}, i \neq j=1 \ldots h
$$

In this case, the MRTS is equal to the ratio of shadow or effective prices. It implies a cost function different from the standard neoclassical one when the constraints are binding. In our study, the specification of the constraints is a problem since its arguments are not well defined; given that we are studying the distortionary impact of multiple policy and institutional constraints on the private manufacturing sector, we cannot explicitly specify them in (6). But estimates of the parameters of the shadow prices, which we discuss below, allow us to determine their cumulative effect on relative price efficiency.

As a first step in estimating the parameters of the unobservable shadow prices, Lau and Yotopolous (1971) and Atkinson and Halverson (1984) approximate these shadow prices by

$$
P_{i}^{e}=k_{i} P_{i}, i=1 \ldots h
$$

where $k_{i}$ is an input-specific factor of proportionality. This approximation can be interpreted as a first-order Taylor series approximation to a general shadow price function $g_{i}\left(P_{i}\right)$, with the properties that $g_{i}(0)=0$ and $\frac{\partial g_{i}\left(P_{i}\right)}{\partial P_{i}} \geq 0$.

If absolute price efficiency exists $k_{i}=1, \forall i .{ }^{9}$ In this situation, the price of each input equals the value of its marginal product. Relative price efficiency, on the other hand, holds if the MRTS equals the ratio of market prices for the corresponding inputs. The latter implies cost minimization, while the former implies both cost minimization and the choice of the efficient level of output. It is not possible, however, to identify absolute price efficiency since the cost function and factor share equations are homogeneous of degree zero in $k_{i}$. Thus, we can only identify relative price efficiency by normalizing one of the $k_{i}$ values to $1 .^{10}$ This is implemented by normalizing one of the $k_{i}$ values to 1 . The estimates are invariant to which shadow price factor is normalized.

The multiplicative $k_{i}$ term is a non-negative parameter that captures inefficiency for input $i$ given market prices. If $k_{i}=1$, firms are price efficient in the use of input $i$ given its relative market prices. If $k_{i}>1$ firms underutilize input $i$, and if $k_{i}<1$ firms overuse the input compared to a cost-minimizing level given market prices. These sorts of non-optimal input use arise because the relative effective prices firms face are higher, in the case of $k_{i}>1$, and lower, in the case of $k_{i}<1$, than the relative market prices.

The shadow cost function, which differs from the neoclassical cost function only in the input price variable, is given by

$$
C^{S}=C^{S}(k P, Q)
$$

\footnotetext{
${ }^{9}$ As an example, for a four-input case, where $h=4$, absolute price efficiency implies $k_{1}=k_{2}=k_{3}=k_{4}=1$.

${ }^{10}$ In this case, if $h=4$ again, relative price efficiency implies that $k_{1}=k_{2}=k_{3}=1$. 
It is used to derive an actual cost function and share equations, used in estimation, as shown in equations (9)-(13). In particular, from the logarithmic differentiation of the shadow cost function and Shepard's Lemma, we obtain

$$
X_{i}=\frac{M_{i}^{S} C^{S}}{k_{i} P_{i}}, i=1 \ldots h
$$

where $X_{i}$ is demand for factor $i, M_{i}^{S}$ is the shadow share of factor $i$, and $C^{S}$ is shadow cost. Using (9), we get an actual cost function, $C^{A}$, from $C^{A}=\sum_{i=1}^{h} P_{i} X_{i}, i=1 \ldots h$, which gives

$$
C^{A}=C^{S} \sum_{i=1}^{h} \frac{M_{i}^{S}}{k_{i}}
$$

Taking the $\log$ of (10) yields

$$
\ln C^{A}=\ln C^{S}+\ln \sum_{i=1}^{h} \frac{M_{i}^{S}}{k_{i}}
$$

The actual share equation for input $i, M_{i}^{A}$, is

$$
M_{i}^{A}=\frac{X_{i} P_{i}}{C^{A}}, i=1 \ldots h
$$

Using (9) and (11), this becomes

$$
M_{i}^{A}=\frac{\frac{M_{i}^{S}}{k_{i}}}{\sum_{i=1}^{h} \frac{M_{i}^{S}}{k_{i}}}, i=1 \ldots h
$$

Using the translog functional form, which provides a second-order approximation to an arbitrary continuously twice-differentiable function, we write the shadow cost function as

$$
\begin{aligned}
\ln C^{S}= & \alpha_{o}+\alpha_{Q} \ln Q+1 / 2 \gamma_{Q Q}(\ln Q)^{2}+\sum_{i} \alpha_{i} \ln \left(k_{i} P_{i}\right)+\sum_{i} \gamma_{i Q} \ln Q \ln \left(k_{i} P_{i}\right) \\
& +1 / 2 \sum_{i} \sum_{j} \gamma_{i j} \ln \left(k_{i} P_{i}\right) \ln \left(k_{j} P_{j}\right)+\delta_{t} t, i, j=1 \ldots h
\end{aligned}
$$

where symmetry restrictions $\gamma_{i j}=\gamma_{j i}$ are imposed. All variable descriptions are as above and $t$ is time trend used to proxy disembodied technological change. The shadow cost function has the same properties as the neoclassical cost function, one of which is linear homogeneity in shadow prices. This implies the following parametric restrictions:

$$
\sum_{i} \alpha_{i}=1, \sum_{i} \gamma_{i Q}=0, \sum_{i} \gamma_{i j}=\sum_{j} \gamma_{i j}=\sum_{i} \sum_{j} \gamma_{i j}=0
$$


From the logarithmic differentiation of the shadow cost function, we obtain the shadow share for input $i$ to be the following:

$$
M_{i}^{S}=\frac{\partial \ln C^{S}}{\partial \ln k_{i} P_{i}}=\alpha_{i}+\gamma_{i Q} \ln Q+\sum_{j} \gamma_{i j} \ln \left(k_{j} P_{j}\right), i, j=1 \ldots h
$$

The actual cost function then becomes

$$
\ln C^{A}=\ln C^{S}+\ln \left\{\sum_{i}\left(\alpha_{i}+\gamma_{i Q} \ln Q+\sum_{j} \gamma_{i j} \ln \left(k_{j} P_{j}\right)\right) / k_{i}\right\}, i, j=1 \ldots h
$$

and the corresponding actual cost share of input $i$ becomes

$$
M_{i}^{A}=\frac{\left(\alpha_{i}+\gamma_{i Q} \ln Q+\sum_{j} \gamma_{i j} \ln \left(k_{j} P_{j}\right)\right) / k_{i}}{\sum_{i}\left(\alpha_{i}+\gamma_{i Q} \ln Q+\sum_{j} \gamma_{i j} \ln \left(k_{j} P_{j}\right)\right) / k_{i}}, i, j=1 \ldots h
$$

We also obtain summary statistics from parameter estimates of the actual cost function and its associated share equations by calculating price elasticities of demand and the Allen-Uzawa partial elasticities of factor substitution. The Allen-Uzawa cross- and own elasticities of substitution are given by

$$
\theta_{i j}=\frac{\gamma_{i j}+M_{i} M_{j}}{M_{i} M_{j}} \text { and } \theta_{i i}=\frac{\gamma_{i i}+M_{i}\left(M_{i}-1\right)}{M_{i}^{2}}
$$

The cross- and own price elasticities are given by

$$
\eta_{i j}=\theta_{i j} M_{j}, \eta_{j i}=\theta_{i j} M_{i} \text { and } \eta_{i i}=\theta_{i i} M_{i}
$$

\subsection{Estimation}

Estimation is based on a nonlinear system containing the four-factor input cost function and the associated share equations. For this type of cost share model the usual practice in empirical work with regard to the stochastic structure involves appending well-behaved error terms to the system of equations; estimation is undertaken with additive, homoscedastic error terms. ${ }^{11}$ Such practice allows the use of conventional estimators. ${ }^{12}$ Brown and Walker (1995), however, indicate that this approach results in theoretically inconsistent models of stochastic behavior. The use of simple

\footnotetext{
11 The usual assumption of well-behaved error terms comes from arguments about unobserved characteristics of firms which are assumed uncorrelated with regressors. As we show in this section, however, when the randomness arises from production technology it leads to input demand or cost share equations which are affected by it. This leads to error terms that are functionally dependent and correlated with right-hand side variables.

${ }^{12}$ See Barten (1969), Berndt (1991, pp. 462-476), Greene (2000, pp. 614-622), and Kmenta and Gilbert (1968).
} 
additive errors either leads to violations of homoscedasticity or restricts the form of the underlying technology by limiting the set of distributions from which they are drawn.

A model of random rational behavior requires that firms minimize cost subject to market forces in input and output markets, and technological constraint. In our case, we also assume that additional constraints in cost minimization arise from the operating environment. The random variation in this process could be due to factors unobservable to the econometrician but known to the firms or due to optimization errors. Brown and Walker (1995) outline the necessary theoretical restrictions on random production models where the randomness arises from the production technology. Under such a scenario, the optimization problem of firms is

$$
\min _{X} P^{\prime} X \text { s.t. } f(X, \varepsilon ; \beta) \leq Q
$$

where all variable definitions are as before, and $\beta$ and $\varepsilon$ are vectors of parameters and random variables, respectively. The cost function that results from this constrained optimization must satisfy the standard regularity conditions detailed in Section 3. These restrictions are important when defining stochastic specifications that are consistent with a random production model.

From the cost function, $C(P, Q, \varepsilon ; \beta)$, we can either obtain input demand equations, $X_{i}=$ $h_{i}(P, Q, \varepsilon ; \beta)$ from $\partial C(\cdot) / \partial P_{i}$, or input share equations, $S_{i}=d_{i}(P, Q, \varepsilon ; \beta)$, from $\partial \ln (C) / \partial \ln \left(P_{i}\right)$. Since we use the latter in our empirical work we will focus on how we address the potential for random production in our optimizing model.

For the cost share model a simple stochastic specification is not appropriate. To see this we first write the simple stochastic share equation as

$$
S_{i}=\overline{d_{i}}(P, Q ; \beta, \eta)+v_{i}(\varepsilon ; \beta, \eta)
$$

where $\eta$ is a vector of shape parameters for the distribution of $\varepsilon$. The natural $\log$ cost function from which $S_{i}$ is derived via Shepard's lemma is

$$
\ln (C)=\bar{D}_{1}(P, Q ; \beta, \eta)+V_{1}(\varepsilon ; \beta, \eta)+K(Q, \varepsilon ; \beta, \eta)
$$

where $\partial \overline{D_{1}}(\cdot) / \partial \ln P_{i}$ results in $\overline{d_{i}}=E\left[d_{i}(\cdot) \mid P, Q\right], \partial V_{1}(\cdot) / \partial \ln P_{i}$ results in $v_{i}$, hence $V_{1}(\cdot)=$ $\sum_{i=1}^{h} v_{i}(\varepsilon ; \beta, \eta) \times \ln \left(P_{i}\right)$, and where $K(Q, \varepsilon ; \beta, \eta)$ is a constant of integration. We can rewrite the cost function as

$$
\ln (C)=\bar{D}_{o}(Q ; \beta, \eta)+\bar{D}_{1}(P, Q ; \beta, \eta)+V_{o}(Q, \varepsilon ; \beta, \eta)+V_{1}(P, Q, \varepsilon ; \beta, \eta)
$$

where $\bar{D}_{o}(Q ; \beta, \eta)=E[K(Q, \varepsilon ; \beta, \eta) \mid Q]$ and $V_{o}(Q, \varepsilon ; \beta, \eta)=K(Q, \varepsilon ; \beta, \eta)-\bar{D}_{o}(Q ; \beta, \eta)$. A simple transformation of the cost function gives us a function with homoscedastic disturbances

$$
\begin{aligned}
& S_{i}=\overline{d_{i}}(P, Q ; \beta, \eta)+v_{i}(\varepsilon ; \beta, \eta) \\
& \ln (C)-\sum_{i=1}^{h} S_{i} \ln \left(P_{i}\right)=\bar{D}_{o}(Q ; \beta, \eta)+\sum_{i=1}^{h} \bar{d}_{i}(P, Q ; \beta, \eta) \times \ln \left(P_{i}\right) \\
& \quad+\bar{D}_{1}(P, Q ; \beta, \eta)+v_{o}
\end{aligned}
$$


Nevertheless, restrictions on the cost shares implied by the unit simplex inequality restrictions of $0 \leq S_{i} \leq 1 \Rightarrow 0 \leq \bar{d}_{i}+v_{i} \leq 1 \Rightarrow-\bar{d}_{i} \leq v_{i} \leq 1-\bar{d}_{i}$ mean that the bounds of the inequalities are functions of $P$ and $Q$. Thus $v_{i}$, the disturbance term of the share equation, either comes from a restricted set of distributions with limited support or is functionally dependent on $P$ and $Q$. This implies

$$
S_{i}=\bar{d}_{i}(P, Q ; \beta, \eta)+v_{i}(P, Q, \varepsilon ; \beta, \eta)
$$

and a disturbance term that is no longer additive and homoscedastic. In fact, $E\left(V V^{\prime}\right)=$ $\Omega(P, Q ; \beta, \Sigma)$ where $\Sigma=E\left(\varepsilon \varepsilon^{\prime}\right)$, which shows the disturbances to be conditionally heteroscedastic. For the cost share model used in this study, we can transform the natural log cost function and estimate the system of equations if we are willing to tolerate potential violations of the unit simplex inequality restrictions. Although this does not alleviate the problem of conditional heteroscedasticity, it is possible to estimate the model ignoring the restrictions but using a heteroscedasticity corrected covariance matrix (HCCM) so that the standard errors are consistent.

In keeping with the approach suggested by Brown and Walker (1995), however, we use a GMM estimator which allows for efficient estimation in the presence of such heteroscedasticity. We obtain initial estimates using NL2SLS, compute the optimal weighting matrix using the Newey-West (1987) estimator, and minimize the GMM criterion function. We adopt the Levenberg-Marquardt method for solving the nonlinear optimization problem (Gill et al., 1981). Partial derivatives of the conditional mean function of the cost system with respect to the parameter vector serve as instruments in setting up the orthogonality conditions (Ruud, 2000, p. 540).

\section{THE DATA}

Private sector manufacturing data were obtained from the Industrial Production Statistics of the Central Agency for Public Mobilization and Statistics (CAPMAS) of Egypt. CAPMAS collects its data using survey questionnaires. Although it began collecting such data in 1937, it was not until 1964/5 that it started publishing them annually. Documents obtained cover a time series extending from the fiscal year 1987/88 to 1995/96, the last year for which data are available at the time of this study.

Industrial data are arranged according to the three broad categories of mining and quarrying, manufacturing, and repair not-classified elsewhere. Our study is based on the manufacturing part of these industrial data. Although establishment-level data are not available, most variables present in the dataset are available at the four-digit ISIC (International Standard Industrial Classification) level. The ISIC is an internationally uniform system for classifying establishments according to their primary activity. Capital and investment data were, however, only reported at the three-digit level. Thus, our empirical work is based on three-digit ISIC level data. A unique features of our study is the novelty of the data. Egyptian private manufacturing activity has not been studied before at this level of disaggregation. The effort to develop the three-digit manufacturing sector dataset required substantial primary data collection and a large commitment of personnel and resources from CAPMAS.

Obvious trade-offs exist in the use of three-digit sector data instead of establishment- or firmlevel data. We have utilized the superlative index number approach of Caves et al. (1982) to aggregate the data to the three-digit level and to the extent that establishments in each sector can be viewed as homogeneous in terms of production technology the use of a cost-minimizing paradigm 
is well established. Possible heterogeneity in the production technology across establishments within a sector and/or across sectors is addressed in estimation using a general covariance structure intended in part to address random effects in the production technologies (Mundlak, 1978). In addition, we view the estimated parameters in the cost model as industry averages and invoke the representative-firm paradigm in interpreting our estimation results using three-digit sectoral data. Morrison and Seigel (1999), among others, point to the large number of research studies that focus on overall trends in a sector or a country and analyze aggregate data using micro models, particularly those based on cost functions. The justifications for such undertakings include the nature of the inquiry at hand, the data available for the inquiry, and the usefulness of the conclusions that can be drawn from it. ${ }^{13}$

Table III provides the complete list of three-digit and two-digit ISIC codes and the industrial activities they represent. It also provides the number of firms at each level of aggregation. The total number of three-digit sectors in the study is 28 . Since nine years of data are available for each sector, the number of observations in the study is 252 .

Given the heterogeneity of the multi-product firms with disparate physical outputs in the data, we use a single aggregate measure of output. This measure aggregates the total value of production by adding up revenue from goods sold, industrial services provided to others, and other revenues. The quantity index of output is obtained by deflating this value by the wholesale price index. The wholesale price index is available at the two-digit level. ${ }^{14}$ Total cost is calculated as the sum of the cost of four different production inputs. These are labor $(L)$, energy $(E)$, materials $(M)$, and capital (K). In particular, for sector $i$ at time period $t$ :

$$
C_{i t}=\sum_{i} P_{i t} X_{i t}, i=L, E, M, K
$$

Data on price and quantity indices are used to compute the cost of the individual production inputs, which make up this total.

The Industrial Production Statistics of CAPMAS provides the total value of intermediate goods and services used by each three-digit sector. We obtain the value of materials by subtracting the value of fuel and electricity from this total. We then deflate the value of materials by the wholesale price index, which serves as the materials price index, to get a quantity index for materials.

The value of fuel and electricity provides a measure of energy consumption for each three-digit sector. The energy price index is based on a consumption weighted average price of all fossil fuels and electricity used by each sector; these data are available at the two-digit level. ${ }^{15}$ The fossil fuel mix includes gasoline, liquefied petroleum gas, natural gas, kerosene, gas oil, and fuel oil. The prices of each of these and of electricity are given in a common LE per ton of oil equivalent (TOE) unit. The energy price faced by each two-digit sector differs owing to variation in the fuel mix and the consumption weight of each type of fuel in the mix which it uses. Thus even if the price of a given energy source is the same for all sectors, the price of energy varies. The

\footnotetext{
${ }^{13}$ For example, there are a large number of studies that examine the effect of public infrastructure on private productive performance based on micro models, including cost functions, using industry-level or aggregate data. Among these are Lynde and Richmond (1993), Nadiri and Mamuneas (1994), and Morrison and Schwartz (1996). In addition, there are also many studies that examine issues of returns to scale using a similar framework. Among these are Park and Kwon (1995), Nadiri and Kim (1996), and Morrison and Seigel (1997, 1999).

${ }^{14}$ Central Bank of Egypt, Annual Report, various issues. 1986/7 = 100.

15 Source: Messiha (1996).
} 
Table III. Two-digit and three-digit ISIC codes and industrial activity

\begin{tabular}{|c|c|c|c|}
\hline 2-digit code & 3-digit code & Industrial activity & No. of firms \\
\hline \multirow[t]{5}{*}{31} & & Food & 3393 \\
\hline & 311 & Food manufacturing & 3162 \\
\hline & 312 & Other food manufacturing & 183 \\
\hline & 313 & Beverage \& liquor & 21 \\
\hline & 314 & Tobacco & 26 \\
\hline \multirow[t]{5}{*}{32} & & Textile \& garments & 1350 \\
\hline & 321 & Manufacture of textile & 820 \\
\hline & 322 & Manufacture of wearing apparels & 375 \\
\hline & 323 & Manufacture of leather products & 57 \\
\hline & 324 & Manufacture of footwear & 98 \\
\hline \multirow[t]{3}{*}{33} & & Wood & 193 \\
\hline & 331 & Manufacture of wood products & 80 \\
\hline & 332 & Manufacture of furniture \& fixture & 113 \\
\hline \multirow[t]{3}{*}{34} & & Paper & 234 \\
\hline & 341 & Manufacture of papers products & 87 \\
\hline & 342 & Printing \& publishing industries & 147 \\
\hline \multirow[t]{6}{*}{35} & & Chemicals & 419 \\
\hline & 351 & Manufacture of industrial chemicals & 24 \\
\hline & 352 & Manufacture of other chemical products & 142 \\
\hline & 354 & Other petroleum \& coal & 9 \\
\hline & 355 & Manufacture of rubber products & 26 \\
\hline & 356 & Manufacture of plastic products & 218 \\
\hline \multirow[t]{4}{*}{36} & & Manufacture of non-metallic products & 547 \\
\hline & 361 & Manufacture of pottery \& china & 16 \\
\hline & 362 & Manufacture of glass \& glass products & 63 \\
\hline & 369 & Manufacture of other non-metallic products & 468 \\
\hline \multirow[t]{3}{*}{37} & & Metal & 103 \\
\hline & 371 & Iron \& steel basic industries & 84 \\
\hline & 372 & Non-ferrous basic industries & 19 \\
\hline \multirow[t]{6}{*}{38} & & Engineering & 613 \\
\hline & 381 & Manufacture of fabricated metal products & 394 \\
\hline & 382 & Manufacture of machinery except electrical & 103 \\
\hline & 383 & Manufacture of electrical machinery & 74 \\
\hline & 384 & Manufacture of transport equipment & 27 \\
\hline & 385 & Manufacture of professional equipment & 15 \\
\hline 39 & 390 & Other manufacture industries & 39 \\
\hline
\end{tabular}

consumption-weighted price for each sector is normalized such that the beginning period's value is set to 100. This fuel price is then used to deflate energy consumption and obtain an energy quantity index for each three-digit sector.

We obtain the wage rate by dividing the total wage bill, which includes pensions and benefits, by total labor, which refers to the number of workers; labor hour data are not available. We normalize this rate to 100 in 1987/88. We then we obtain a labor quantity index by dividing the value of labor, or total wages, by this price index.

Capital stock values are obtained by applying the perpetual inventory method:

$$
k(t)=(1-\delta) \times k(t-1)+I(t)
$$

where $k(t)$ is the capital stock at time $t, k(t-1)$ is the previous period's value, $I(t)$ is current investment, called capital addition by CAPMAS, and $\delta$ is the rate of depreciation of the capital stock. We use a depreciation rate of $6.9 \%$ calculated on the assumption of a 10-year geometrically 
declining rate. In order to calculate the capital stock series, starting in 1987/88, we use the 1970/71 $k$-stock as a benchmark.

This measure of capital is deflated by the rental price of capital, $P(t)$. We use the following version of the rental price formulation:

$$
P(t)=\left(\frac{1}{1-u(t)}\right)\left\{p_{\mathrm{I}}(t-1) \times r(t)+\delta \times p_{I}(t)\right\}+p_{I}(t) \times c(t)
$$

where $u(t)$ is the effective corporate tax rate at time $t, r(t)$ is the nominal interest rate, $p_{I}(t)$ is the capital goods deflator, $\delta$ is the depreciation rate of the capital stock, and $c(t)$ is the effective property tax rate. The terms reflect the cost of capital, replacement cost, and indirect taxes, respectively (Christensen and Jorgenson, 1969). A study by EL Samalouty (1999) gives the effective corporate tax rate as $27 \%$ for the manufacturing sector, which we use. The property tax rate is estimated to be $16 \%$ and includes rental, security, and occupancy taxes.

Summary statistics of variables used in the study are presented in Table IV. On average, the data indicate that the cost share of energy in total cost is the lowest at 3.5\% and that of materials is the highest at $74 \%$. The cost share of labor and capital are also low at $8.7 \%$ and $13.8 \%$, respectively. These compare with cost shares from the US Bureau of Labor Statistics for aggregate US manufacturing in 1995 of $45 \%$ for labor, $20 \%$ for capital, $4 \%$ for energy, and $31 \%$ for materials and the cost shares that average $27 \%$ for labor, $5 \%$ for capital, $4 \%$ for energy, and $63 \%$ from materials for the seminal Berndt and Wood (1975) 1947-1971 data on aggregate US manufacturing.

\section{EMPIRICAL RESULTS}

\subsection{Parameter Estimates and Hypotheses Tests}

We estimate the system of equations (17) and (18) by GMM after dropping the share equation for the labor input. ${ }^{16}$ The shadow price factors $k_{i}, i=L, K, M, E$ are assumed to be input specific, but not sector specific because it is not possible to identify them for each individual cross-section. As a result, estimates reflect their mean cross-sectional values. To the extent that firms face the same policy burden, as is the case here, this is a reasonable restriction.

The system of equations we estimate can be characterized as the shadow price model. As noted in Section 2, the estimation identifies relative price efficiency by normalizing the price of one of the shadow price factors at a value of 1 . We choose the shadow price of capital, $k_{K}=1$, for this normalization. If relative price distortions are absent, such that $k_{i}=1, \forall i$, then we have the market price model. The absence of relative price inefficiency is a testable hypothesis, which we investigate and report on below.

Table V contains parameter estimates from the shadow price model for the entire period. The effect of the operating environment is reflected in parameter estimates for shadow price factors that are not equal to 1: the $k_{L}, k_{E}$ and $k_{M}$ estimates are all statistically significantly different from 1 .

Tables VI and VII provide the price elasticities of demand and factor substitution elasticities at the data mean. The price elasticities of the factor inputs are $44 \%$ for labor, $26 \%$ for materials, $11 \%$

\footnotetext{
${ }^{16}$ Standard panel treatments for the multivariate system (cf. Sickles, 1985) were considered. However, with our highly nonlinear system an additive fixed effects estimator (28 additional intercepts for each of the four equations) was not feasible. Our GMM estimator is designed to deal in part with the correlated errors from a random effects specification of additive intercept heterogeneity.
} 
Table IV. Summary statistics

\begin{tabular}{|c|c|c|c|c|c|}
\hline Measure & Unit & Mean & SD & Max. & Min. \\
\hline Value of energy & 1000 LEs & 17,578 & 36,141 & 270,308 & 102 \\
\hline Energy price & Index & 318 & 205 & 744 & 100 \\
\hline Energy quantity & Index & 62 & 116 & 857 & 0.16 \\
\hline Wage bill & 1000 LEs & 43,650 & 59,034 & 344,515 & 1,048 \\
\hline Labor price & Index & 150 & 65 & 446 & 50 \\
\hline Labor quantity & Index & 273 & 344 & 1,686 & 10 \\
\hline Value of materials & 1000 LEs & 373,066 & 505,609 & $3,176,818$ & 3,855 \\
\hline Materials price & Index & 200 & 68 & 346 & 69 \\
\hline Materials quantity & Index & 1,823 & 2,169 & 11,854 & 45 \\
\hline Value of capital stock & 1000 LEs & 69,800 & 109,279 & 623,538 & 1 \\
\hline Capital price & Index & 257 & 112 & 397 & 100 \\
\hline Capital quantity & index & 289 & 475 & 3,437 & 0.01 \\
\hline Cost & 1000 LEs & 504,262 & 668,968 & $4,250,369$ & 5,801 \\
\hline Output price & Index & 200 & 68 & 346 & 69 \\
\hline Output quantity & Index & 2,889 & 3,333 & 19,236 & 67 \\
\hline
\end{tabular}

In 1990: central bank rate $=2.0$ LE/US $\$$ and free market rate $=3.2$ LE/US $\$$.

Table V. Parameter estimates from the shadow model

\begin{tabular}{lcr}
\hline Coefficient & Parameter estimates & $t$-Ratios \\
\hline$\alpha_{o}$ & 1.153 & 14.69 \\
$\alpha_{Q}$ & 0.646 & 26.87 \\
$\alpha_{L}$ & 0.44 & 19.43 \\
$\alpha_{M}$ & 0.264 & 6.72 \\
$\alpha_{E}$ & 0.11 & 5.37 \\
$\alpha_{K}$ & 0.186 & 6.51 \\
$\delta_{t}$ & -0.02 & -12.84 \\
$\gamma_{Q Q}$ & 0.03 & 10.17 \\
$\gamma_{L Q}$ & -0.023 & -11.61 \\
$\gamma_{M Q}$ & 0.014 & 4.73 \\
$\gamma_{E Q}$ & 0.011 & 6.86 \\
$\gamma_{k Q}$ & -0.003 & -1.74 \\
$\gamma_{L L}$ & -0.027 & -4.10 \\
$\gamma_{I M}$ & -0.038 & -4.40 \\
$\gamma_{L E}$ & 0.034 & 7.45 \\
$\gamma_{l K}$ & 0.031 & 5.41 \\
$\gamma_{M M}$ & 0.08 & 4.68 \\
$\gamma_{M E}$ & -0.02 & -3.94 \\
$\gamma_{M K}$ & -0.022 & -4.80 \\
$\gamma_{K K}$ & -0.015 & -1.24 \\
$\gamma_{K E}$ & 0.007 & 0.83 \\
$\gamma_{E E}$ & -0.021 & -3.39 \\
$k_{L}$ & 2.577 & 7.58 \\
$k_{M}$ & 0.086 & 36.25 \\
$k_{E}$ & 4.45 & 6.24 \\
\hline & & \\
\hline
\end{tabular}

The $t$-ratios for $k^{\prime}$ s are for the null that they are equal to 1 . 
Table VI. Price elasticities of demand at the mean of the data

\begin{tabular}{lrcrr}
\hline & Labor & Materials & Capital & Energy \\
\hline Labor & -0.657 & 0.023 & 0.321 & 0.313 \\
& $(-41.26)$ & $(1.11)$ & $(23.20)$ & $(28.30)$ \\
Materials & 0.082 & -0.194 & 0.051 & 0.036 \\
& $(1.11)$ & $(-1.31)$ & $(1.26)$ & $(0.84)$ \\
Capital & 0.532 & 0.051 & -0.816 & 0.277 \\
& $(23.20)$ & $(2.70)$ & $(-16.31)$ & $(7.97)$ \\
Energy & 0.554 & 0.03 & 0.277 & -0.861 \\
& $(28.30)$ & $(1.39)$ & $(7.49)$ & $(-31.85)$ \\
& & & & \\
\hline
\end{tabular}

Values in parentheses are $t$-stats.

Table VII. Allen-Uzawa elasticities of substitution at the data mean

\begin{tabular}{lrrrr}
\hline & Labor & Materials & Capital & Energy \\
\hline Labor & -1.611 & & & \\
& $(-41.27)$ & & & \\
Materials & 0.201 & -1.681 & & \\
& $(1.11)$ & $(-1.31)$ & & \\
Capital & 1.304 & 0.208 & -3.319 & \\
& $(23.20)$ & $(1.26)$ & $(-16.31)$ & \\
Energy & 1.357 & 0.261 & 1.125 & -3.726 \\
& $(28.30)$ & $(1.39)$ & $(7.49)$ & $(-31.85)$ \\
\hline
\end{tabular}

Values in parentheses are $t$-stats.

for energy, and $19 \%$ for capital. The substitution elasticities show all pairs of inputs to be substitutes and thus we can expect relative price distortions to increase the demand for factors whose effective prices are lower as producers substitute towards them. For instance, as the discussion in the next section suggests, the price of materials relative to all factor inputs is distorted downwards and thus we expect substitution towards materials. This is what we observe in the data.

We have checked the properties of the shadow cost function to ensure it corresponds to a well-behaved cost function. Linear homogeneity holds since it is imposed for estimation. For monotonicity, we look at the signs of the fitted factor share equations. These are all positive at all data points. For concavity, we examine the signs of the principal minors of the Hessian matrix at the grand mean of the data. They have the expected alternating signs. The fitted cost function is also positive at all data points.

Our test of the over-identifying restrictions gives a value of 109.8 , which has a $\chi^{2}$ distribution with 66 degrees of freedom; we have 92 instruments and 26 parameters, resulting in 66 degrees of freedom. This $\chi^{2}$ value is above the critical value of 86 for 66 degrees of freedom at the 0.05 level. Therefore, we accept the null that the instruments are valid.

Table VIII contains results from hypotheses tests on the market price model versus the shadow price model, constant returns to scale, homogeneity, and homotheticity. We use the Wald test statistic, which has a $\chi_{J}^{2}$ distribution with $J$ degrees of freedom, where $J$ is the number of restrictions, to test these hypotheses.

The null hypothesis of relative price efficiency or the market price model, where $k_{L}=k_{M}=$ $k_{E}=1$, is rejected at the $1 \%$ level. The production technology is restricted to be homothetic if the 
Table VIII. Results of hypotheses tests

\begin{tabular}{lccc}
\hline Null hypothesis & $J$ & LR test statistic & $\chi_{J}^{2}$ (value at 5\% level) \\
\hline Market price model & 3 & 3402 & 11.34 \\
Constant RTS & 6 & 1565.60 & 16.81 \\
Homogeneity & 5 & 37.50 & 15.09 \\
Homotheticity & 4 & 348.64 & 13.28 \\
\hline
\end{tabular}

cost function can be written as a separable function of factor prices and output. The homotheticity restriction implies $\gamma_{i Q}=0, \gamma$ for $i=L, K, M, E$, and all factor price and output interaction terms drop out of the cost function, thus preserving the slope of the isoquants along every ray from the origin. In this case returns to scale measures the relationship between total cost and output along an expansion path unaffected by factor prices. The production technology is further restricted to be homogeneous if returns to scale does not change as output increases. In this case, in addition to the homotheticity restrictions, the second-order term in output is dropped: $\gamma_{Q Q}=0$. As a result, the average cost function does not change as output varies and thus cannot take on a u-shaped form. In addition to the above restrictions, if $\gamma_{Q}=1$, then we have constant returns to scale. The test results in Table VIII show that we can reject homotheticity, homogeneity, and constant returns to scale. Therefore, we retain all second-order terms in the cost function.

\subsection{Relative Price Efficiency, Cost, and Factor Shares}

The shadow price factors indicate the existence of relative price inefficiency. For the normalization $k_{K}=1$ we have $k_{L}=2.58, k_{M}=0.086$, and $k_{E}=4.45$. These parameters indicate the extent and direction of relative price inefficiencies (recall equations (6) and (7)). Thus an estimate of 2.58 for $k_{L}$ implies that the effective price ratio or MRTS of labor to capital exceeds the market price ratio of these two inputs since $f_{L} / f_{K}=2.58 \times P_{L} / P_{K}$. Similarly, the ratio of marginal products of energy to capital exceeds the ratio of their market prices, while that between materials and capital falls below the ratio of their market prices. The extent of relative price inefficiencies, which these parameters indicate, increases cost above an efficient level that would have prevailed in their absence.

Since the shadow price parameter estimates are invariant to the choice of shadow factor normalization, they have implications for the MRTS of all pairs of inputs. Table IX presents these values along with the corresponding $t$-ratios. The $t$-ratios indicate that all the values are statistically significantly different from 1.

The values in the table indicate that the relative shadow price of energy is the highest, followed by the relative shadow price of labor, and then capital; the relative shadow price of materials is the lowest. This finding implies that energy market distortions have the greatest impact on

Table IX. Relative price ratios between all pairs of inputs

\begin{tabular}{lrlrrr}
\hline$f_{\mathrm{E}} / f_{\mathrm{L}}=1.73$ & $(3.39)$ & $f_{\mathrm{E}} / f_{\mathrm{K}}=4.45$ & $(6.25)$ & $f_{\mathrm{E}} / f_{\mathrm{M}}=51.73$ & $(7.90)$ \\
$f_{\mathrm{L}} / f_{\mathrm{E}}=0.58$ & $(9.15)$ & $f_{\mathrm{L}} / f_{\mathrm{K}}=2.58$ & $(7.58)$ & $f_{\mathrm{L}} / f_{\mathrm{M}}=29.97$ & $(11.97)$ \\
$f_{\mathrm{K}} / f_{\mathrm{L}}=0.39$ & $(19.74)$ & $f_{\mathrm{K}} / f_{\mathrm{E}}=0.22$ & $(27.75)$ & $f_{\mathrm{K}} / f_{\mathrm{M}}=11.63$ & $(8.25)$ \\
$f_{\mathrm{M}} / f_{\mathrm{L}}=0.03$ & $(96.70)$ & $f_{\mathrm{M}} / f_{\mathrm{K}}=0.09$ & $(36.56)$ & $f_{\mathrm{M}} / f_{\mathrm{E}}=0.02$ & $(163.50)$ \\
\hline
\end{tabular}

Values in parentheses are $t$-stats. 
relative price inefficiency in the private manufacturing sector of Egypt. It shows the divergence of $k_{E}$ from unity is greatest, which suggests that the policy of setting the domestic price of energy substantially below the world price has the biggest impact on relative price distortions. Energy price ceilings are non-budgetary subsidies that are at the root of the distortion captured by our model. While these subsidies have an economy-wide effect, in terms of the opportunity cost of lost revenue, they are also likely to affect the true cost of the energy input faced by the firms in the private sector. In effect, the unsustainability of the subsidies appears to have created a divergence between expected prices and actual prevailing prices.

Several developments in the economy strongly point to this possibility. Egypt undertook expanded commercial production of oil in the 1960s, which accelerated following the oil price increase of 1974. As a result the country enjoyed an unprecedented boom in foreign exchange earnings in the 1970s and the early 1980s. Foreign exchange earnings also grew as a result of tourism, the Suez Canal, and the large remittances from Egyptian expatriates residing in the oilrich Gulf countries. Along with the increase in foreign exchange earnings, the country enjoyed rapid GDP growth of $9.3 \%$ per year during this period.

With the decline of world oil prices in the mid 1980s, and coincident decreases in remittances from Egyptian expatriates, foreign currency earnings declined markedly. GDP growth also declined to about $4.5 \%$ per year in the mid 1980s. The general decline in economic growth and foreign currency earnings resulted in increasing levels of fiscal deficits and debt-to-GDP ratio. In addition, concerns about existing reserves and hence future production possibilities of oil surfaced at this time. During the 'boom' years of the 1970s and early 1980s the costs created by the government's energy policy were not identified. By the mid 1980s, however, there was a growing concern about the economic burden caused by the price structure for energy. It is thus reasonable to deduce that producers in the economy perceived the subsidy to be unsustainable. Industrial sector producers were even more likely to have had this perception since highly subsidized energy inputs had encouraged energy-intensive production such as energy-intensive consumer goods, food processing, and industrial raw materials such as steel and aluminum (Lahiri, 1989).

The results also indicate that labor market regulations have the second most significant impact on relative price inefficiency. Rigid labor market policies, including barriers to dismissals and guaranteeing public sector employment for all secondary school graduates, seem to raise the effective relative price of labor for private sector manufacturing firms. Financial sector and tax policies also play a role, though a relatively less important one, in determining relative price inefficiency. In particular, the result suggests that financial sector and tax disincentives to investment raise the MRTS between capital and materials inputs above their market price ratio.

We study the extent of distortions, engendered by the policy constraints, by comparing estimated factor shares under relative price inefficiency and relative price efficiency. Relative price efficiency is assessed by using the market price model or restricting $k_{i}=1, \forall i$, in the generalized cost model. Table $\mathrm{X}$ presents factor share estimates for these two cases, at the data mean.

It is evident that the shares of labor, energy, and capital in total cost are lower due to the policy constraints by $20 \%, 15 \%$, and $1 \%$, respectively, while that of materials is higher by $37 \%$.

We can also assess welfare loss that results from the policies under consideration by examining what cost, employment, and value added would be in their absence. ${ }^{17}$ We undertake such analysis,

\footnotetext{
${ }^{17}$ Value added is an output measure obtained by subtracting the materials quantity measure from the output quantity index. 
Table X. Efficient and inefficient factor shares at the data mean

\begin{tabular}{lccc}
\hline & Efficient & Inefficient & \% Difference \\
\hline Share $L$ & 0.291 & 0.089 & $-20 \%$ \\
Share $M$ & 0.375 & 0.745 & $37 \%$ \\
Share $E$ & 0.182 & 0.029 & $-15 \%$ \\
Share $K$ & 0.151 & 0.137 & $-1 \%$ \\
\hline
\end{tabular}

Table XI. Welfare loss: values at the data mean (1000 LEs)

\begin{tabular}{lrrr}
\hline & Efficient & Inefficient & $\%$ Difference \\
\hline Cost & 269,335 & 501,124 & $62 \%$ \\
Labor & 523.47 & 296.16 & $-57 \%$ \\
Value added & 2383.51 & 1020.46 & $-85 \%$ \\
\hline
\end{tabular}

once again, by examining the values of these figures under relative price inefficiency and efficiency. Table XI presents these at the data mean.

The values in the table indicate that there is substantial welfare loss due to the policies that distort relative prices. At the data mean, labor demand and value added are lower by $57 \%$ and $85 \%$, respectively, while cost is higher by $62 \%$. The loss in cost efficiency is, on average, $40 \%$ of the value of manufacturing output; this value ranges from a high of $45 \%$ to a low of $25 \%$.

The results in Tables $\mathrm{X}$ and XI indicate the divergence of factor shares, cost, labor demand and value added from their efficient levels, which would have prevailed in the absence of relative price inefficiency. To investigate the effect of the policy environment on factor shares and factor demand, though, we examine the divergence of estimated actual values from their shadow counterparts. Table XII presents these values at the data mean.

The unobserved shadow cost shares reflect optimizing behavior that incorporate the effect of the operating environment. These values are what we need to focus on if we are interested in influencing firms' behavior by altering the institutional framework under which they operate. They reflect the decision of firms based on their perception of the relative effective cost of inputs; as stated earlier, the relative effective cost of energy is the highest, followed by that of labor and then capital. These shadow share results suggest that firms' spending is higher on factors whose relative effective prices are greater than observed. Conversely, firms' spending is lower on the factors they perceive as being relatively cheap. The shadow cost share of materials is $12 \%$, while the observed share is $75 \%$ at the data mean. This suggests that private manufacturing firms save on materials

Table XII. Estimated actual and shadow values of factor shares at the data mean

\begin{tabular}{lccc}
\hline & Shadow values & Actual values & \% Difference \\
\hline Share $L$ & 0.408 & 0.089 & $-32 \%$ \\
Share $M$ & 0.115 & 0.745 & $63 \%$ \\
Share $E$ & 0.231 & 0.029 & $-20 \%$ \\
Share $K$ & 0.246 & 0.137 & $-11 \%$ \\
\hline
\end{tabular}


spending based on the lower effective price of this input. On the other hand, the shadow cost share of labor is significantly higher at $41 \%$ than the observed share at $9 \%$, at the data mean, as is the shadow cost share of energy at $27 \%$ than the observed share at $3 \%$. Similarly, the shadow share of capital is higher at $25 \%$ than the observed share at $14 \%$. These indicate that the private sector firms spend more on energy, labor and capital owing to the higher relative effective prices of these inputs.

As indicated in Section 2, if $k_{i}>1$ firms under-use and if $k_{i}<1$ firms over-use input $i$ compared to a cost-minimizing amount given relative market prices. Values of $k_{E}=4.45$ and $K_{L}=2.58$ indicate that firms under-use energy ${ }^{18}$ and labor below levels that minimize cost given their relative market prices. On the other hand, a value of $k_{M}=0.09$ indicates firms over-use materials beyond levels that minimize cost given its relative market price. We can examine the extent of input overand under-use, holding output constant, by comparing shadow to actual factor demands, obtained by deflating actual and shadow factor costs by market prices. Table XIII presents these values at the data mean.

On average, the firms' actual labor and energy use are $95 \%$ and $149 \%$ below the shadow or optimal levels and their materials use is $245 \%$ above the shadow or optimal amount, given relative market prices.

Since we are interested in the impact of the reforms of the early 1990s, we carry out similar analysis by period; period 1 covers the years 1987/88-1990/91, and period 2 covers the years 1991/92-95/96. Table XIV presents the parameter estimates by period.

Once again the estimates of the shadow factors indicate the direction and magnitudes of the relative price inefficiencies in the two periods. As before, the ratio of marginal products between energy and capital, and between labor and capital, exceed their market price ratios in both periods. The MRTS between materials and capital are similarly below this pair's market price ratios in the two periods. Most importantly, we observe the degree of distortions to be greater in period 1 than in period 2. In particular, $k_{L}=2.16$ in period 1 while it is 1.65 in period 2 , and $k_{E}=6.48$ in period 1 while it is 4.18 in period $2 .{ }^{19}$ In addition, although $k_{M}$ is still significantly below 1 in period 2, at 0.16 , it is closer to it than the period 1 value of 0.04 . These indicate that although relative price inefficiencies remain in period 2, they are lower in that period.

We compare the effect of the policy constraints in the two periods, in order to assess the effect of reforms initiated in period 2, by comparing actual and shadow shares in both periods. Table XV presents these values at the data mean.

The direction of distortions is the same in both periods and mirrors what we see for the entire period. However, the magnitudes of these distortions are lower in period 2 than in period 1 . In particular, the actual labor share is below the shadow share by $31 \%$ in period 1 while it is so

Table XIII. Estimated actual and shadow values of factor demands at the data mean (1000 LEs)

\begin{tabular}{lcrr}
\hline & Shadow values & Actual values & \% Difference \\
\hline Labor & 763.26 & 296.16 & $-95 \%$ \\
Materials & 161.48 & 1868.44 & $245 \%$ \\
Energy & 203.76 & 45.79 & $-149 \%$ \\
\hline
\end{tabular}

\footnotetext{
18 This implies that production should have been even more energy-intensive than was noted by some observers (Lahiri, 1989).

${ }^{19}$ As for the entire period, energy market distortions have the largest effect on relative price inefficiencies in both periods. 
Table XIV. Parameter estimates from the shadow model by period

\begin{tabular}{|c|c|c|c|c|}
\hline Coefficient & Period 1 estimates & $t$-Ratios & Period 2 estimates & $t$-Ratios \\
\hline$\alpha_{o}$ & 1.268 & 3.72 & 1.794 & 25.93 \\
\hline$\alpha_{Q}$ & 0.377 & 16.93 & 0.428 & 21.22 \\
\hline$\alpha_{L}$ & 0.301 & 6.42 & 0.32 & 26.14 \\
\hline$\alpha_{M}$ & 0.192 & 1.15 & 0.205 & 6.93 \\
\hline$\alpha_{E}$ & 0.229 & 5.62 & 0.214 & 10.04 \\
\hline$\alpha_{K}$ & 0.278 & 2.21 & 0.26 & 6.70 \\
\hline$\delta_{t}$ & 0.04 & 11.04 & -0.021 & -8.55 \\
\hline$\gamma_{Q Q}$ & 0.076 & 21.88 & 0.066 & 20.99 \\
\hline$\gamma_{L Q}$ & 0.006 & 2.36 & -0.017 & -12.27 \\
\hline$\gamma_{M Q}$ & -0.002 & -0.89 & 0.019 & 5.98 \\
\hline$\gamma_{E Q}$ & 0.002 & 0.85 & 0.006 & 3.13 \\
\hline$\gamma_{k Q}$ & -0.006 & -1.55 & -0.008 & -7.16 \\
\hline$\gamma_{L L}$ & 0.004 & 0.43 & -0.008 & -1.44 \\
\hline$\gamma_{l M}$ & -0.012 & -0.94 & -0.031 & -5.05 \\
\hline$\gamma_{L E}$ & 0.003 & 0.36 & 0.023 & 7.88 \\
\hline$\gamma_{l K}$ & 0.006 & 0.86 & 0.015 & 3.72 \\
\hline$\gamma_{M M}$ & 0.027 & 1.05 & 0.059 & 6.60 \\
\hline$\gamma_{M E}$ & -0.007 & -0.75 & -0.012 & -3.35 \\
\hline$\gamma_{M K}$ & -0.008 & -1.35 & -0.016 & -3.86 \\
\hline$\gamma_{K K}$ & 0.0002 & 0.01 & -0.003 & -0.24 \\
\hline$\gamma_{K E}$ & 0.002 & 0.17 & 0.004 & 0.54 \\
\hline$\gamma_{E E}$ & 0.002 & 0.12 & -0.016 & -2.32 \\
\hline$k_{L}$ & 2.162 & 1.84 & 1.649 & 3.18 \\
\hline$k_{M}$ & 0.042 & 16.58 & 0.163 & 13.97 \\
\hline$k_{E}$ & 6.479 & 2.12 & 4.183 & 4.60 \\
\hline
\end{tabular}

The $t$-ratios for $k$ 's are for the null that they are equal to 1 .

Table XV. Fitted shares and cost by period

\begin{tabular}{|c|c|c|c|c|c|c|}
\hline & \multicolumn{3}{|c|}{ Period 1} & \multicolumn{3}{|c|}{ Period 2} \\
\hline & Actual values & Shadow values & $\%$ diff. & Actual values & Shadow values & $\%$ diff. \\
\hline Share $L$ & 0.397 & 0.087 & $-31 \%$ & 0.293 & 0.099 & $-19 \%$ \\
\hline Share $M$ & 0.068 & 0.768 & $70 \%$ & 0.216 & 0.736 & $52 \%$ \\
\hline Share $E$ & 0.267 & 0.019 & $-25 \%$ & 0.257 & 0.034 & $-22 \%$ \\
\hline Share $K$ & 0.268 & 0.126 & $-14 \%$ & 0.235 & 0.131 & $-10 \%$ \\
\hline Cost & 329,403 & 155,282 & $75 \%$ & 677,805 & 377,500 & $59 \%$ \\
\hline
\end{tabular}

by only $19 \%$ in period 2 . Similarly, actual energy and capital shares are lower than their shadow counterparts by $25 \%$ and $14 \%$ respectively in period 1 while they are so by $22 \%$ and $10 \%$ in period 2. Actual materials share exceeds the shadow share by $70 \%$ in period 1 and by $52 \%$ in period 2. We also find improvement in the difference between actual and shadow cost in period 2 .

To examine which policy changes we discussed earlier have had the biggest effect on reducing relative price inefficiency in period 2, we look at changes in relative prices of energy, labor, and capital to materials in both periods. Table XVI presents these values.

As indicated above, relative price inefficiencies are lower in period 2 than in period 1 . This finding further demonstrates that policy reforms initiated in period 2 have reversed, to some extent, the inefficiencies engendered by earlier policy constraints. It is also evident that the relative price 
Table XVI. Relative prices by period

\begin{tabular}{lrcc}
\hline & Period 1 values & Period 2 values & $\%$ Difference \\
\hline$f_{\mathrm{E}} / f_{\mathrm{M}}$ & 162 & 26.12 & $182.50 \%$ \\
$f_{\mathrm{L}} / f_{\mathrm{M}}$ & 54 & 10.31 & $165.60 \%$ \\
$f_{\mathrm{K}} / f_{\mathrm{M}}$ & 25 & 6.25 & $138.60 \%$ \\
\hline
\end{tabular}

of energy has improved the most and that of capital the least, which suggests that energy policy reforms have had the greatest effect. This outcome is promising since energy market policies appear to be, according to our empirical exercise, the biggest source of relative price inefficiency.

\section{CONCLUDING REMARKS}

The use of a generalized cost function allows us to study the impact of policy constraints on the structure of production. Our findings indicate that the total cost of Egypt's private manufacturing sector firms was higher as a result of these constraints. In particular, we find that relative price inefficiencies that result from the operating environment lead to uneconomical factor demands that increase total cost. The contribution to cost increase is greatest from distortions in the energy input market, followed by those in the labor and capital input markets. Looking at the welfare loss engendered by these distortions, we see that for a labor abundant country like Egypt, which has a high unemployment rate, correcting relative price distortions is highly desirable; correcting such distortions will elicit the needed supply response to enhance the economic output and employment needs of the sector. Generally, reforms appear to have had favorable impact on effective cost and relative price inefficiency reductions, as indicated by firms' performance during the second period. In particular, the relative price inefficiency of energy has declined the most in period 2, which suggests energy market reforms have had the biggest impact.

\section{ACKNOWLEDGEMENTS}

The authors would like to thank members of the Development Economic Policy Reform Analysis Project (DEPRA), USAID/Egypt and the Ministry of Economy of Egypt. Funding was provided under USAID Contract No. 263-00-96-00001-00, for the Development Economic Policy Reform Analysis Project, Nathan Associates, Inc. Project No. B444-003. Sickles was the project's Senior Research Coordinator. The authors also thank Dr Suzanne Messiha and the CompTeam for their valuable suggestions and contributions to the collection and overseeing of all the data series on which this paper is based. Bryan W. Brown and Mahmoud El-Gamal provided needed criticisms and insights. Earlier versions of the paper were presented at workshops at Indiana University, Union College, SUNY Albany, and the Texas Econometrics Camp. The research and findings do not necessarily reflect the opinions or conclusions of Nathan Associates, USAID, or the Ministry of Economy of Egypt. The usual caveat applies.

\section{REFERENCES}

Abdel-Khalek G. 2001. Stabilization and Adjustment in Egypt. Edward Elgar: Cheltenham, UK. Annual Report. Central Bank of Egypt, various issues. 
Assaad R. 1996. Structural adjustment and labor market reform in Egypt. In Economic Liberalization and Privatization in Socialist Arab Countries, Hopfinger H (ed.). Justus Perthes Verlag Gotha: Stuttgart.

Assaad R. 1997. The effects of public sector hiring and compensation policies on the Egyptian labor market. World Bank Economic Review 11(1): 85-118.

Atkinson SE, Halvorsen R. 1984. Parametric efficiency tests, economies of scale, and US electric power generation. International Economic Review 25: 647-662.

Barten AP. 1969. Maximum likelihood estimation of a complete system of demand equations. European Economic Review 1: 7-73.

Berndt ER. 1991. The Practice of Econometrics: Classic and Contemporary. Addison-Wesley: Reading, MA.

Berndt ER, Wood D. 1975. Technology, prices, and the derived demand for energy. Review of Economics and Statistics 57: 376-384.

Brown BW, Walker MB. 1995. Stochastic specification in random production models of cost-minimizing firms. Journal of Econometrics 66(1-2): 175-205.

Caves D, Christensen LR, Diewert W. 1982. Output, input and productivity using superlative index numbers. Economic Journal 92: 73-96.

Christensen LR, Jorgenson DW. 1969. The measurement of US real capital input. Review of Income and Wealth 15: 293-320.

El Samalouty G. 1999. Corporate tax and investment decisions in Egypt. Working Paper No. 35, Egyptian Center for Economic Studies.

Evanoff DD, Israilevich PR, Merris RC. 1990. Relative price efficiency, technical change and scale economies for large commercial banks. Journal of Regulatory Economics 2: 281-298.

Fallon PR, Lucas RE. 1991. The impact of changes in job security regulations in India and Zimbabwe. World Bank Economic Review 5(3): 395-413.

Faris Al-Faris AR. 1997. Energy-pricing policies in Arab countries: impacts of structural adjustment programs. OPEC Review 1997(December): 245-260.

Gill PE, Murray W, Wright MH. 1981. Practical Optimization. Academic Press: London.

Giugale MM, Mobarak H. 1996. The rationale for private sector development in Egypt. In Private Sector Development in Egypt, Giugale MM, Mobarak H (eds). American University in Cairo Press: Cairo.

Good DH, Nadiri MI, Sickles RC. 1991. The structure of production, technical change and efficiency in a multiproduct industry: An application to U.S. airlines. NBER Working Paper No. 3939.

Good DH, Nadiri MI, Sickles RC. 1997. Index number and factor demand approaches to the estimation of productivity. In Handbook of Applied Econometrics. Vol. II: Microeconomics, Pesaran MH, Schmidt P (eds). Blackwell: Oxford, UK; 14-80.

Greene WH. 2000. Econometric Analysis. Prentice-Hall: Englewood Cliffs, NJ.

Harik I. 1997. Economic Policy Reform in Egypt. University Press of Florida: Gainesville, FL.

Industrial Production Statistics. Central Agency for Public Mobilization and Statistics of Egypt, various years.

International Trade Administration (ITA). 1999. Country Commercial Guide to Egypt. prepared by the American Embassy in Egypt, July.

Kmenta J, Gilbert RF. 1968. Small sample properties of alternative estimators of seemingly unrelated regression. Journal of the American Statistical Association 63: 1180-1200.

Lahiri S. 1989. On certain aspects of energy pricing issues and policies in Egypt. Journal of Energy and Development 13(2): 223-238.

Lasserre P, Ouellette P. 1994. Factor demands, cost functions, and technology measurements for regulated firms. Canadian Journal of Economics 27: 218-242.

Lau LJ, Yotopoulos PA. 1971. A test for relative efficiency and application to Indian agriculture. American Economic Review 61: 94-109.

Lynde C, Richmond J. 1993. Public capital and long-run costs in UK manufacturing. Economic Journal 103(419): 880-893.

Messiha S. 1996. Impact of Energy Price Increase on the Prices of Industrial Products. Organization for Energy Conservation and Planning (OECP). Cairo, Egypt.

Morrison CJ, Schwartz AE. 1996. State infrastructure and productive performance. American Economic Review 86(5): 1095-1111.

Morrison CJ, Siegel D. 1997. External capital factors and increasing returns in US manufacturing. Review of Economics and Statistics 79(4): 647-654. 
Morrison Paul CJ, Siegel D. 1999. Estimation of scale economies underlying growth and productivity: the empirical implications of data aggregation. Southern Economic Journal 65(4): 739-756.

Mundlak Y. 1978. On the pooling of time series and cross section data. Econometrica 64: 69-85.

Nadiri MI, Kim S. 1996. R\&D, production structure and productivity growth: a comparison of the US, Japanese and Korean manufacturing sectors. NBER Working Paper No. 5506.

Nadiri MI, Mamuneas TP. 1994. The effects of public infrastructure and R\&D capital on the cost structure and performance of US manufacturing industries. Review of Economics and Statistics 76(1): $22-37$.

Newey WK, West KD. 1987. A simple, positive semi-definite, heteroskedasticity and auto correlation consistent covariance matrix. Econometrica 55: 703-708.

Park SR, Kwon JK. 1995. Rapid economic growth with increasing returns to scale and little or no productivity growth. Review of Economics and Statistics 77(2): 332-351.

Posusney MP. 2003. Globalization and labor protection in oil-poor Arab countries. Global Social Policy 3(3): 267-297.

Ruud PA. 2000. An Introduction to Classical Econometric Theory. Oxford University Press: Oxford.

Sickles RC. 1985. A nonlinear multivariate error components analysis of technology and specific factor productivity growth with an application to the US airlines. Journal of Econometrics 27: 61-78.

Sickles RC, Getachew L. 2000. An analysis of Egypt's private manufacturing productivity and efficiency growth. In Private Sector Contribution to Egypt's Productivity and Growth, Nathan Associates. Report submitted to USAID: Cairo, Egypt.

Tesche J, Tohamy S. 1994. A note on economic liberalization and privatization in Hungry and Egypt. Comparative Economic Studies 36(2): 51-72.

Tybout JR. 2000. Manufacturing firms in developing countries: how well do they do and why? Journal of Economic Literature 38: 11-44.

U.S. Department of State. 2002. 2001 Country Report on Economic Policy and Trade Practices (Egypt). Released by the Bureau of Economic and Business Affairs, February.

World Bank. 1994. Private Sector Development in Egypt: The Status and the Challenges. Washington, DC. 